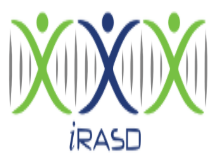

iRASD Journal of Management

Volume 3, Number 3, 2021, Pages 268 - 284

\title{
Managing Diversity Through Leadership and Emotional Intelligence in the Banking Sector of Pakistan: A Moderating Role of Organizational Culture
}

\author{
Burhan Sami ${ }^{1}$, Ahmed Saeed Minhas ${ }^{2}$, Usman Ahmad ${ }^{3}$, Kashif Akram ${ }^{4}$ \\ ${ }^{1}$ PhD Scholar, Management Science Department, DHA Suffa University, Karachi, Pakistan, Email: \\ burhansami007@gmail.com \\ 2 Pro-Vice Chancellor, Management Science Department, DHA Suffa University, Karachi, Pakistan. \\ ${ }^{3}$ Assistant Professor, Management Science Department, DHA Suffa University, Karachi, Pakistan. \\ ${ }^{4}$ Assistant Professor, Department of Leadership and Business Management, IBMAS, Islamia University Bahawalpur,
} Pakistan.

\section{ARTICLE INFO}

\section{Article History:}

Received:

Revised:

Accepted:

November 26, 2021

December 28, 2021

Available Online: December 29,

\section{Keywords:}

Leadership Styles

Emotional Intelligence

Diversity

Organizational Culture

PLS-SEM

\section{ABSTRACT}

The diversity of workforce is increasing due to globalization therefore, it is crucial for organizations to manage the workforce diversity however, there is dearth of literature on workforce diversity management. This study examines the effects of transformational leadership, transactional leadership, and emotional intelligence on workplace diversity. The moderation effect of organizational culture has also been examined. The quantitative approach has been used in data collection, and 182 sample responses have been gathered from the banking industry employees of Pakistan. The data has been analyzed by employing PLS-SEM. The results have shown that transformational and transactional leadership positively and insignificant affect workplace diversity. However, emotional intelligence has a positive and significant effect on workplace diversity. Besides, organizational culture has a positive and significant moderation effect between transactional leadership and workplace diversity. The organizational culture has a negative but insignificant moderation effect between transformational leadership and workplace diversity. The organizational culture has a negative but insignificant moderation effect between emotional intelligence and diversity. Managers are recommended to ensure transparency when identifying roles and expectations of the task amongst employees. Secondly, establish reward systems upon effective outcomes. Thirdly, state the punishments with utmost clarity.

(c) 2021 The Authors, Published by iRASD. This is an Open Access article under the Creative Common Attribution Non-Commercial 4.0

Corresponding Author's Email: burhansami007@gmail.com

\section{Introduction}

Over the years, populations all around the globe have been diversified due to several geopolitical, environmental, and socioeconomic factors. Diversification has consequently influenced the ways human beings live, interact and work with one another. As a response, organizations are employing new strategies to utilize the growing diversity to gain competitive advantages effectively. More and more organizations in the modern era are actively integrating diversity into their recruitment and operational activities to ensure the best possible performance of the firm (Cletus, Mahmood, Umar, \& Ibrahim, 2018). Diversity management has become a popular term in the modern world and management practice. Various policies have been developed by organizations that are directed to promote effective diversity management. Diversity can act as a force to elicit emotions inside and outside the workplace. This is one of the main reasons diversities has remained an essential 
feature in management literature for many years. Workplace diversity signifies different features and variations that are ascribable to individuals, such as physical attributes, age, gender, ethnicity, social and economic backgrounds(Scarborough, Lambouths III, \& Holbrook, 2019). Considering diversity dynamics like creativity and flexibility can provide numerous benefits to the organizations to maintain their competitiveness. Moreover, organizations that prioritize a diverse workforce enjoy many resolutions to the faced problems because a diverse workforce contributes to generating new ideas to cope with the challenges(Oyewunmi, 2018).

Diversity management refers to the voluntary actions of organizations that are devised to induce higher inclusion of the employees belonging to different backgrounds into informal and formal organizational structures through purposeful planning (Shifnas \& Sutha, 2016). Andoh, Ghansah, Okogun-Odompley, and Benuwa (2019) described that organizations which adopt diversity management practices as a source of development and innovation are more likely to facilitate their implementations with greater efforts, persistence, and focus. Leaders and top management of the firms also recognize the importance of workplace diversity for overall business approach and strategic management practices. Schaffer (2019)highlighted that the managers appreciate workplace diversity as it would help the organizations design the right pathways to deal with the higher levels of complexity.

Diversity specifies the differences between people in an organization involving age, race, gender, personality, organizational function, cognitive style, and educational background. Diversity is a major contributing factor to gain a competitive advantage as it is an essential source of innovation and creativity. However, diversity can also cause misunderstanding, conflict, and suspicion in the workplace, resulting in poor quality of work, loss of competitiveness, absenteeism, and low morale (Tamunomiebi \& John-Eke, 2020). In addition, the possibilities of conflicts arising due to unfair treatment, sexism, and glass ceiling problem in a diverse workplace are relatively higher (Kamales \& Knorr, 2019). Negative attitudes of the employees regarding workplace diversity also pose a significant challenge for the firms because it may give rise to the rejection of many workplace diversity initiatives and prejudice (Anglim, Sojo, Ashford, Newman, \& Marty, 2019).

The pervading influence of diversity in organizations cannot be ignored in recent times. The concept of diversity has transformed from being a legal or governmental obligation to a strategic priority, and diversity has become the basis of attaining sustainable performance. However, scant display of diversity or embracing diversity as a concept does not guarantee success. Organizations must effectively manage diversity by actively encouraging, celebrating, and valuing the workforce diversity (Kundu \& Mor, 2017). Furthermore, one of the crucial challenges faced by organizations is the management of an increasingly diverse workforce. Still, very few studies have been carried out to understand the role of organizational leaders in enhancing diversity management in organizations ( $\mathrm{Ng} \&$ Sears, 2020).

The study has examined the effect of transformational leadership, transactional leadership, and emotional intelligence on workplace diversity with the moderating role of organizational culture in the banking sector of Pakistan. Thus, the research questions are;

- What are the effects of transformational leadership, transactional leadership, and emotional intelligence on workplace diversity?

- Does organizational culture moderate the effect of transformational leadership, transactional leadership, and emotional intelligence on workplace diversity?

\section{Literature Review}

According to various scholars, there is no generally accepted definition of leadership (Aydin \& Ceylan, 2009) because different scholars have developed the definitions of leadership based on their understanding. Transformational-transactional leadership theory is widely used in recent studies to describe and assess the behaviors of leaders working in an organization (Riaz \& Haider, 2010). Transformational leadership is the process that transforms and changes individuals, organizations, and teams. Transformational leadership 
broadens the employees' interests and induces acceptance and awareness of organizational goals and objectives. Bass (1990) Identified four dimensions of transformational leadership in his theory: inspirational motivation, individualized consideration, intellectual stimulation, and idealized influence.

On the contrary, transactional leadership refers to the spirited exchange between leaders and subordinates (Burns, 1995). Based on the transformational-transactional theory the transactional leadership is characterized by contingent management and rewards. Transactional leadership provides the employees with clarified pathways to attain their goals. Moreover, transactional leadership contributes to making the employees extrinsically satisfied (Podsakoff, Bommer, Podsakoff, \& Mackenzie, 2006).

Bass (1990) described transformational leadership and transactional leadership as major contributing factors in stimulating, energizing, and inspiring employees to adopt a diversified approach to cope with the challenges that eventually result in workplace diversification. Another perspective is offered by the social exchange theory proposed by Homans (1958). Social exchange theory suggests that beneficial exchange based on mutual considerations contributes to social stability. Individuals feel obliged to respond if they favorably treat and reciprocate (Blau, 1968) by engaging in social exchanges categorized by long-term emotional commitment and attachments (Masterson, Lewis, Goldman, \& Taylor, 2000). Thus, when organizations use diversity management practices, it positively develops the organizational culture where employees reciprocate fair treatment. Increased productivity, commitment, and engagement arise in response to the social exchange eventually add up to the emotional intelligence of the employees (Gouldner, 1960).

\subsection{Transformational Leadership}

Transformational leadership is considered a form that derives competitiveness and motivates the employees (followers) to perform beyond their expectations. This is likely implied by transforming values, aspirations, needs, and priorities (Imran, Fatima, Zaheer, Yousaf, \& Batool, 2012). Transformational leadership is the core competence factor that determines the identity of a leader in terms of defining the change and the corresponded vision that is encompassed along with it (Manzoor et al., 2019). Transformational leadership is likely considered the constraint that develops the organizational performance through the collective assortment of the team members with a cultivated set of values directed towards a collective goal (Yang, 2014). Moreover, the organizational goals are envisaged with prior clarity and prior determination that inclines the heightened consciousness of the employees towards a directed set of goals to be attributed (Bastari, Eliyana, \& Wijayanti, 2020; Hermans, 2021).

\subsection{Transactional Leadership}

Transactional leadership relatively corresponds to an exchange relationship often described as the transactional process derived between the leader and the employees (subordinates) (Shapira-Lishchinsky, 2018). In terms of prior clarity, it can be determined as the process which contrives the leader to ordain a reward system mainly comprised of cash to ascertain the actions of the followers (Kittikunchotiwut, 2019). This leadership is likely induced with the certainty in maintaining sufficient functionality to ensure the compatibility of the followers to be directed into actions in the short term, reducing the administration's strain. In the context of transactional leader Bass and Bass Bernard (1985) defined "individual that can comprehend the existing system and the culture with the concurrency in risk avoidance time management as well as efficacy to maintain control." Transactional leadership is likely comprised of the certainty of two discernible behavior elements contrived as a contingent reward and exceptional management (Elramalli, 2020).

\subsection{Emotional Intelligence}

Emotional intelligence is likely inclined as the interrelated components of emotions and social competencies directed towards the skills and attributes of an individual through which definite behavior is generated (Hersing, 2017). Emotional intelligence helps in the cultivation of the monitoring ability of an individual through which the certainty of other people are controlled and discriminated in order to use the emotional information to 
cultivate thinking and behavioral correspondence (Boruah, 2018). While on the other hand, Kumari and Priya (2017) discussed emotional intelligence as an individual's tendency through which "communication, recognizing, describing, identifying and understanding the emotions" is concerned. Emotional intelligence is likely applied in every field, as it is conceived as an influential factor to understand the driving force of an individual's behavior related to a certain work element.

\subsection{Organizational Culture}

Organizational culture conspires as the pattern of values, beliefs, and relative expectations shared by an organization (Canagasuriam \& Roulin, 2021). The organizational culture is likely disseminated from the organizational culture of the other organization in the context of the collectively programmed mind of the individuals varied in an organization (Setyaningrum, 2017). In contrast, organizational culture can be identified as the measuring scale through which the perception of the individuals can be exclaimed in terms of perceiving their organization relatively. The comprising factor that is ordained in the context of revealing organizational culture is that it shapes the direction of human attitudes as well as the behaviors through which the encompassing element of organizational activity is recognized. The functionality of the organizational culture can be perceived with declarative consistency in the context of formulating a positive impact on the organization through the prevention of cultural dysfunction in the organization (Marlina et al., 2021).

\subsection{Workplace Diversity}

Workplace diversity is constrained as a holistic construct that denotes the existential difference between the people working in the organization. Workplace diversity is constrained by the differences and similarities between the employees in demographics (Suharnomo, Wahyudi, \& Wikaningrum, 2017). The demographics such as age, gender, ethnicity, a cultural region, nationality, etc. According to Cletus et al. (2018), workplace diversity can be defined as the identity of individuals and ascertaining their retrospective race, age, class, ethnicity, physical ability, sexual orientation, and the spiritual practices that they comprehend (Tamunomiebi \& John-Eke, 2020). Workplace diversity is relatively inclined to accumulate competitive advantage with the certainty of a creative, adaptive, and ever-changing environment. Workplace diversity is relatively inclined as an influential factor that ascertains the tendency of organizational leaders to contemplate the dynamics of the business environment relatively (Chitra, 2017).

\subsection{Transformational Leadership and Workplace Diversity}

McCallaghan, Jackson, and Heyns (2019) studied the variance of workplace diversity and transformational leadership in South African companies. The study highlighted the impact of transformational leadership to positively predict quality workplace diversity climate, which could incline prosperity to the future leaders and the managers leveraged in an organization. Likewise, Taylor (2015) studied the correspondence of organizational leaders in terms of their relativity with employee retention, and a partake of competitive advantage. The focus of the study was relatively on determining the aspects that are cultivated through transformational leadership and the diverse workplace environment. Thus, the study results determined that the transformational leadership interacted with workplace diversity was conversed as significant. Furthermore, Jackson, Heyns, and McCallaghan (2019) explored the organizational diversity climate and its consistency with the antecedents and replicated employee outcomes. The study focused on the leadership style; workplace diversity constrained organizational commitment, revealing the relationship between transformational leadership and workplace diversity to be significantly correlated.

H1: Transformational leadership has a significant effect on workplace diversity.

\subsection{Transactional Leadership and Workplace Diversity}

Cote (2017) evaluated various objective leadership styles in order to determine their effectiveness in the context of strategic planning. The study focused on the variance of two 
diverse leadership styles, effective and dark side leadership styles. Transactional leadership was comprised in the context of an effective leadership style. The study highlighted the significance of effective leadership in the context of a prompting constraint through which competitive advantage could be developed, and trends can be managed in the diverse workplace environment. Brown, Brown, and Nandedkar (2019) focused on transformational and transactional leadership styles to examine the factors that affected the perception of diversity management in tertiary educational institutes. The study highlighted the relevancy between transactional leadership and diversity workplace management perceived by higher education employees. Ogbor and Orishede (2018) also exclaimed the relationship between ethical leadership and workplace diversity. The component of ethical leadership comprised transformational as well as a transactional leadership style. This conferred the variance and importance of transactional leadership to be constrained as a potential amplifier of workplace diversity.

H2: Transactional leadership has a significant effect on workplace diversity.

\subsection{Emotional Intelligence and Workplace Diversity}

Arnold (2019) discussed the relationship between emotional intelligence and workplace diversity in the context of women and minor communities. The study highlighted that the subject of emotional intelligence in relationship with workplace diversity is likely exclaimed based on demographic variability. The study revealed the relationship to be insignificant and significant based on demographic variability and highlighted that the relationship is constrained to be limited. Oyewunmi (2018) studied the relationship between emotional intelligence and workplace diversity competence. The study focused on Southwest Nigeria and highlighted the relationship between emotional intelligence and workplace diversity management competence to be positively associated. In comparison, Anglim studied the relationship between personality values and cognitive abilities with workplace diversity. The results revealed that personality values and cognitive abilities implied a positive relationship with workplace diversity.

H3: Emotional Intelligence has a significant effect on workplace diversity.

\subsection{Transformational Leadership, Organizational Culture, and Workplace Diversity}

Organizational culture is conversed to be one of the primary elements that derive the workplace diversity in a cultivated environment. Bana (2016) studied the effect of organizational culture on workplace diversity in Kenyan public universities. The implication of the relationship was conversed based on perception devised from the senior administrators. The study determined that the disparity in the workplace of public universities are determined to be challenging. Thus the study determined the relationship between organizational culture as well as workplace to be significant. On the other hand, Uche, Onokala, Okundalaiye, George, and Oni (2020) also discussed the imperative effect of workplace diversity and organizational culture in the Nigerian maritime industry. The study relatively reflected the relationship between organizational culture and workplace diversity to be effective.

Furthermore, Ali (2021) also signified the relationship between organizational culture and workforce diversity in Saudi Arabian universities. The organizational culture can be considered a moderator among the relationship between transformational leadership and workplace diversity based on the emphasized relationship discussed above. Thus the hypothesis can be determined as:

H4: Organizational Culture moderates the relationship between transformational leadership and workplace diversity.

\subsection{Transactional Leadership, Organizational Culture, and Workplace Diversity}

Leadership competencies associated with workplace diversity encourage skilled competencies in the employees, which is likely ordained with organizational culture. In this 272 
regard, Farashah and Blomqusit (2021) studied the cultural strategies and their relative effectiveness in Sweden, a well-developed country, through which the diversified strategies are contemptuous. The study relatively revealed that the emphasis of the organizational culture ordains the influence over diversified workplace strategies. Furthermore, Sethi, Vito, and Ongbanouekeni (2021) highlighted the impact of leadership and organizational culture in a diversified work environment. The study highlighted that the organizations should suffice with the workforce dynamics influenced by the organizational culture to promote an equitable workplace culture. Likely, Miller, Ngunjiri, and LoRusso (2017) determined the influence of organizational culture to develop and contribute to diversity and inclusion in the workplace, cultivating the organization to an extent.

H5: Organizational Culture moderates the relationship between transactional leadership and workplace diversity.

\subsection{Emotional Intelligence, Organizational Culture, and Workplace Diversity}

Emotional intelligence is likely insinuated as the factor that composes practical consideration in productivity and business performance. This is likely influenced by the organizational culture as well as workplace diversity. Tamunomiebi and John-Eke (2020) highlighted the importance of heterogeneous work organizations, which are likely determined based on organizational culture and are contempt towards workplace diversity. This signifies the importance of organizational culture and workplace diversity in terms of the prior learning-work environment. Obuma and Worlu (2017) emphasized the importance of organizational culture in disseminating nepotism and favoritism with the certainty of implying workplace diversity can vary improved performance, particularly in the banking sector. The study also highlighted the implicit effect of positive attitude to be directed in the condition, which is considered as the trait confided in emotional intelligence. Furthermore, the implication of workplace diversity with versatile organizational culture can likely promote sustainable business advantage development, and the relationship is likely enhanced within the employees Suharnomo et al. (2017). Thus, the hypothesis can be considered as:

H6: Organizational Culture moderates the relationship between emotional intelligence and workplace diversity.

\section{Methodology}

There are two research choices named qualitative and quantitative choice. The quantitative choice focuses on objective measurements regarding the research topic and conducts analysis based on the statistical technique. Besides, it is based on numeric data as the data can be gathered through the survey method and can generate statistical results (Kothari, 2004). This choice can be conducted systematically as it allows the researcher to collect the data sequentially and does not require high management. This process can be conducted in a relatively cost and time-efficient way and can also gather a large sample size as well (Blessing \& Chakrabarti, 2009).

Similarly, this choice allows the researcher to conduct hypotheses testing and test the theory as well. In addition, the deductive approach refers to the process in which the researcher reasons from the different statements and generates a logic-based conclusion. This approach can be helpful in hypothesis development based on a theory as it focuses on its testing (Creswell, 2002). Hence, the quantitative-deductive approach has been used in this research as it can help in generating a generalized set of results.

Moreover, the causal design focuses on examining the variables and their relationships with each other in a cause-effect manner. This design can be conducted in a non-experimental way, and it cannot allow the presence of any manipulative or external data (Sekaran \& Bougie, 2010). Similarly, it helps the researcher understand the phenomenon in the presence of conditional statements as it identifies the effects of specific causes (Saunders, Lewis, \& Thornhill, 2009). Therefore, causal design has been used to identify the presence of causation between the variables. 
The banking sector of Pakistan has been growing as there exist 26 commercial banks, 11 microfinance, and six developing banks in the country. The performance in the last decade has increased as their revenues went from 6,516 billion to PKR 15,134 billion by the end of 2018 (Memon, Qureshi, \& Jokhio, 2020). Therefore, this research has aimed to target the banking sector employees in Pakistan by employing simple random sampling.

The current research has five variables in which organizational culture contains five items adapted from Sashkin and Rosenbach (1990). Like, "In my organization, people are flexible and adaptable when changes are necessary." Transformational leadership contains four items adapted from Mickson, Anlesinya, and Malcalm (2020). For example, "My leader provides vision and sense of mission, instills pride, gains respect and trust." Transactional leadership contains four items adapted from Mickson et al. (2020). For instance, "My leader concentrates his/her full attention on dealing with mistakes, complaints or failures. "Emotional intelligence contains five items adapted from Libbrecht, Beuckelaer, Lievens, and Rockstuhl (2014). Like, "I have a good understanding of my own emotions." The workplace diversity contains five items adapted from De Meuse and Hostager (2001). For instance, "I believe that diversity is fair at my workplace."

\section{Data Analysis}

This research has applied the PLS-SEM technique to examine the moderation hypotheses and generated significant results.

There are 182 respondents of this research, of which 87 were male and 95 female respondents. The 40 respondents were from less than 24 years, 46 respondents were from 25 - 34 years, 53 respondents were from 35 - 44 years, and 43 were from 45 and above. Forty-seven respondents were from firms with less than 500 employees, 50 respondents were from firms with 501 - 1000 employees, 49 respondents were from firms with 1001 2000 employees, and 36 respondents were from more than 2000 employees. Among the 182 respondents, 48 were from the deputy manager, 50 were from the manager, 43 respondents were from the senior manager, and 41 respondents were from the assistant manager. The 47 respondents were from firms with less than three years' experience, 44 respondents were from 3 to 5 years of experience, 47 respondents were from 6 to 8 years of experience, and 44 respondents were from above eight years of experience.

\subsection{Measurement Model}

Measurement model refers to the statistical estimation modeling of the relationship between indicators and latent constructs related and congruent based on theory (J F Hair, Sarstedt, Hopkins, \& Kuppelwieser, 2014). PLS-SEM estimates measurement model based on indicator reliability and their statistical significance for construct validity (J F Hair, Ringle, \& Sarstedt, 2011) while Cronbach's alpha, composite reliability (CR), and average variance extracted (AVE) are the measures for convergent validity (J F Hair, Matthews, Matthews, \& Sarstedt, 2017). Following table 1 shows the result of the measurement model comprehensively.

J F Hair, Hult, Ringle, and Sarstedt (2016) recommended that indicator reliability should be higher than 0.60 with statistically significant at 5 percent while J F Hair et al. (2011) suggested that alpha should be higher than 0.70, CR should be higher than 0.80 , and AVE should be greater than 0.50 for a considerable degree of convergence. In this regard, the above table showed that the least indicator reliability was found of 0.664 (TRL1) while all indicators were statistically significant at 5 percent. Similarly, transactional leadership has the least alpha coefficient of $0.781, \mathrm{CR}$ of 0.856 and AVE of 0.601 and therefore, all latent constructs have achieved substantial degree of convergence with their indicators. 
Table 1

Measurement Model

\begin{tabular}{lllllll}
\hline Latent Constructs & Items & Loading & Prob. & Alpha & CR & AVE \\
\hline Emotional Intelligence & EI1 & 0.866 & 0.000 & 0.871 & 0.911 & 0.718 \\
& EI2 & 0.788 & 0.000 & & & \\
& EI3 & 0.875 & 0.000 & & & \\
Organizational Culture & EI5 & 0.859 & 0.000 & & & \\
& OC1 & 0.956 & 0.000 & 0.869 & 0.886 & 0.664 \\
& OC2 & 0.684 & 0.000 & & & \\
Transformational Leadership & OC3 & 0.887 & 0.000 & & & \\
& OC5 & 0.698 & 0.000 & & & \\
& TL1 & 0.792 & 0.000 & 0.871 & 0.906 & 0.708 \\
& TL2 & 0.819 & 0.000 & & & \\
Transactional Leadership & TL3 & 0.863 & 0.000 & & & \\
& TL4 & 0.890 & 0.000 & & & \\
& TRL1 & 0.664 & 0.000 & 0.781 & 0.856 & 0.601 \\
& TRL2 & 0.690 & 0.000 & & & \\
\multirow{4}{*}{ Workplace Diversity } & TRL3 & 0.870 & 0.000 & & & \\
& TRL4 & 0.854 & 0.000 & & & \\
& WI1 & 0.966 & 0.000 & 0.952 & 0.969 & 0.912 \\
& WI2 & 0.957 & 0.000 & & & \\
\hline
\end{tabular}

\subsection{Discriminant Validity}

The purpose of discriminant validity is to statistically check the unrelatedness between latent constructs that are theoretically different (Campbell \& Fiske, 1959). PLSSEM has three different methods for discriminant validity, including Fornell and Larcker (1981) criterion, cross loadings, and HTMT ratio illustrated in the following tables.

Table 2

Discriminant Validity using FLC

\begin{tabular}{llllll}
\hline & $\begin{array}{l}\text { Emotional } \\
\text { Intelligence }\end{array}$ & $\begin{array}{l}\text { Organizational } \\
\text { Culture }\end{array}$ & $\begin{array}{l}\text { Transactional } \\
\text { Leadership }\end{array}$ & $\begin{array}{l}\text { Transformational } \\
\text { Leadership }\end{array}$ & $\begin{array}{l}\text { Workplace } \\
\text { Diversity }\end{array}$ \\
\hline EI & 0.848 & & & & \\
OC & -0.519 & 0.815 & & & \\
TRL & -0.523 & 0.562 & 0.775 & & \\
TL & -0.512 & 0.709 & 0.628 & 0.842 & 0.955 \\
WD & 0.751 & -0.226 & -0.418 & -0.229 & \\
\hline
\end{tabular}

Fornell and Larcker (1981) suggested that the square-rooted AVE for latent constructs should be higher than the correlation coefficients of other constructs in the model (Ab Hamid, Sami, \& Sidek, 2017). Therefore, the bold diagonal values in the above table 2 shows that all latent constructs had achieved considerable unrelatedness with other constructs.

Cross loadings is a method of discriminant validity for assessing the statistical difference between latent constructs based on indicator reliability (J F Hair, Ringle, \& Sarstedt, 2013). It has been recommended that indicators should have higher loadings in their constructs rather than other latent constructs (Joseph F Hair, Risher, Sarstedt, \& Ringle, 2019). The table 3 depicts that all indicators have higher reliability in their constructs, manifesting considerable discrimination with other constructs.

HTMT ratio has been proposed by Henseler, Ringle, and Sarstedt (2015) as a novel and comprehensive method for discriminant validity in PLS-SEM based on multi-trait estimation between latent constructs (Ab Hamid et al., 2017). In this regard, Henseler, Hubona, and Ray (2016); Henseler et al. (2015) suggested that constructs with HTMT ratio below the 0.85 thresholds should achieve a substantial degree of divergence with other constructs. The table 4 displays that the highest HTMT ratio of 0.802 was found between emotional intelligence (EI) and workplace diversity (WD) and therefore, discriminant validity was achieved based on the HTMT ratio. 
Table 3

Discriminant Validity using Cross loadings

\begin{tabular}{lccccc}
\hline & $\begin{array}{l}\text { Emotional } \\
\text { Intelligence }\end{array}$ & $\begin{array}{l}\text { Organizational } \\
\text { Culture }\end{array}$ & $\begin{array}{l}\text { Transactional } \\
\text { Leadership }\end{array}$ & $\begin{array}{l}\text { Transformational } \\
\text { Leadership }\end{array}$ & $\begin{array}{l}\text { Workplace } \\
\text { Diversity }\end{array}$ \\
\hline EI1 & 0.866 & -0.424 & -0.359 & -0.461 & 0.661 \\
EI2 & 0.788 & -0.614 & -0.525 & -0.676 & 0.436 \\
EI3 & 0.875 & -0.532 & -0.542 & -0.547 & 0.660 \\
EI5 & 0.859 & -0.274 & -0.389 & -0.170 & 0.726 \\
OC1 & -0.548 & 0.956 & 0.570 & 0.662 & -0.260 \\
OC2 & -0.342 & 0.684 & 0.346 & 0.462 & -0.082 \\
OC3 & -0.387 & 0.887 & 0.467 & 0.664 & -0.169 \\
OC5 & -0.310 & 0.698 & 0.324 & 0.507 & -0.003 \\
TL1 & -0.438 & 0.750 & 0.551 & 0.792 & -0.170 \\
TL2 & -0.305 & 0.512 & 0.441 & 0.819 & -0.042 \\
TL3 & -0.379 & 0.502 & 0.429 & 0.863 & -0.170 \\
TL4 & -0.495 & 0.589 & 0.611 & 0.890 & -0.255 \\
TRL1 & -0.357 & 0.291 & 0.664 & 0.578 & -0.225 \\
TRL2 & -0.351 & 0.468 & 0.690 & 0.357 & -0.212 \\
TRL3 & -0.426 & 0.517 & 0.870 & 0.552 & -0.415 \\
TRL4 & -0.478 & 0.451 & 0.854 & 0.478 & -0.375 \\
WI1 & 0.682 & -0.131 & -0.399 & -0.114 & 0.966 \\
WI2 & 0.670 & -0.174 & -0.451 & -0.188 & 0.957 \\
WI5 & 0.798 & -0.340 & -0.349 & -0.354 & 0.942 \\
\hline
\end{tabular}

Table 4

Discriminant Validity using HTMT Ratio

\begin{tabular}{llllll}
\hline & $\begin{array}{l}\text { Emotional } \\
\text { Intelligence }\end{array}$ & $\begin{array}{l}\text { Organizational } \\
\text { Culture }\end{array}$ & $\begin{array}{l}\text { Transactional } \\
\text { Leadership }\end{array}$ & $\begin{array}{l}\text { Transformational } \\
\text { Leadership }\end{array}$ & $\begin{array}{l}\text { Workplace } \\
\text { Diversity }\end{array}$ \\
\hline EI & & & & \\
OC & 0.573 & & & & \\
TRL & 0.647 & 0.632 & 0.731 & & \\
TL & 0.584 & 0.770 & 0.459 & 0.218 & \\
WD & 0.802 & 0.190 & & & \\
\hline
\end{tabular}

\subsection{Predictive Relevance}

The following table 5 shows the predictive relevance of endogenous latent construct in the model. In this regard, $\mathrm{R}^{2}$ and adjusted $\mathrm{R}^{2}$ have been estimated using the PLS algorithm while $\mathrm{Q}^{2}$, based on Geisser (1975); Stone (1974) technique, has been estimated using PLS blindfolding at six omissions (J F Hair et al., 2013).

\section{Table 5}

Predictive Relevance

\begin{tabular}{llll}
\hline Endogenous Construct & $\boldsymbol{R}^{\mathbf{2}}$ & Adjusted $\boldsymbol{R}^{\mathbf{2}}$ & $\mathbf{Q}^{\mathbf{2}}$ \\
\hline Workplace Diversity & 0.631 & 0.623 & 0.614 \\
\hline
\end{tabular}

The above table has shown that workplace diversity has been explained up to 63.1 percent $\quad\left(R^{2}=0.631\right)$ with moderate relevance of 61.4 percent $\left(Q^{2}=0.614\right)$, providing that the model has a substantial predictive orientation (J F Hair et al., 2014). 


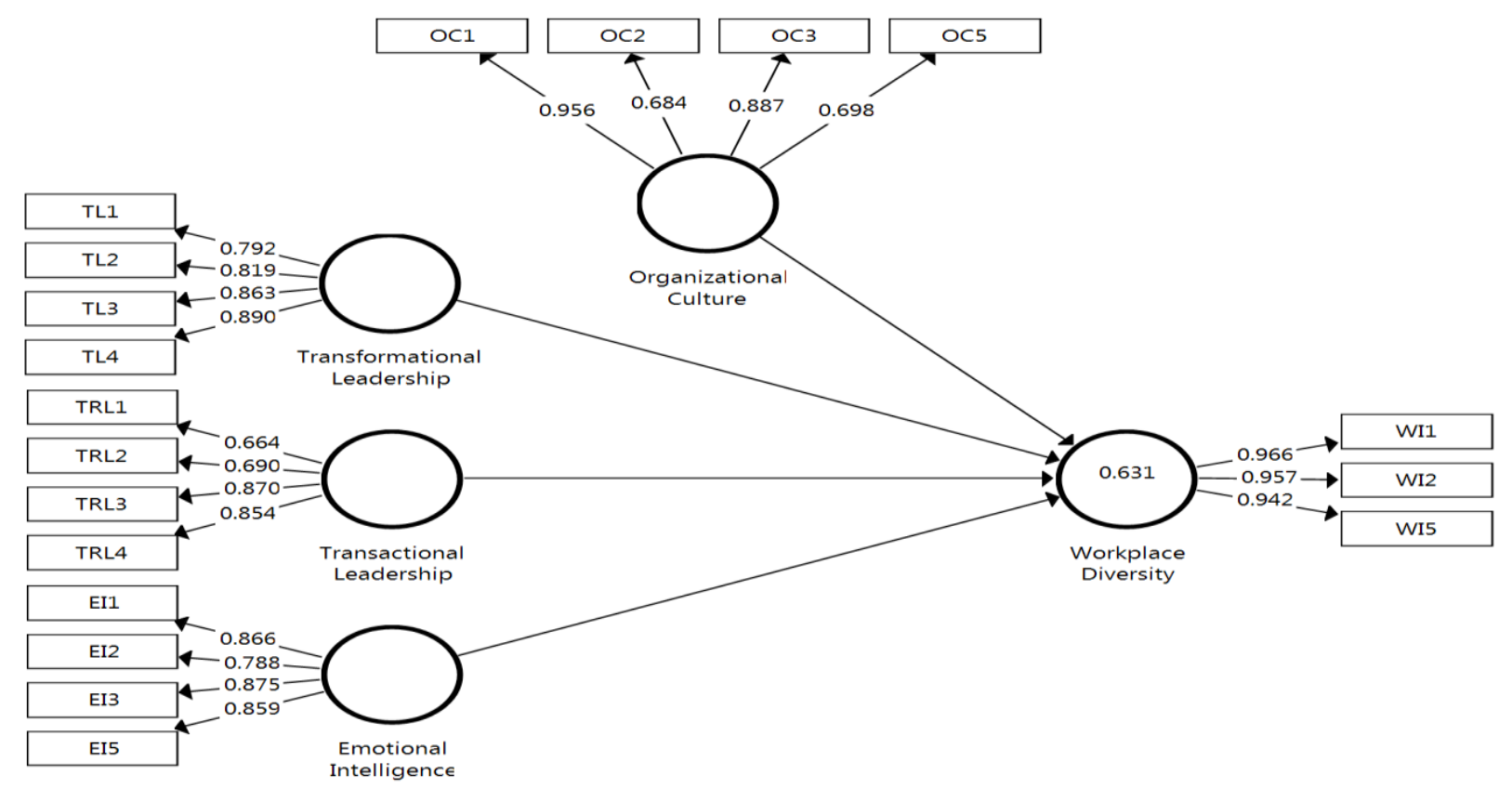

Figure 1: PLS Algorithm

\subsection{Structural Model}

The statistical model for estimating the relationship between latent constructs is a structural model in PLS-SEM (J F Hair et al., 2011). However, Henseler and Fassott (2010) recommended that PLS-SEM has a significance of estimating moderation analysis, and therefore, the following tables have shown hypothesis-testing using path analysis based on PLS bootstrapping at 5000 subsamples and 5 percent statistical significance.

\section{Table 6}

\section{Hypothesis-Testing using Path Analysis}

\begin{tabular}{lcccc}
\hline Path Relationships & Estimate & S. D. & T-Stats & Prob. \\
\hline H1: TL -> Workplace Diversity & 0.052 & 0.121 & 0.428 & 0.334 \\
H2: TRL -> Workplace Diversity & 0.055 & 0.089 & 0.613 & 0.270 \\
H3: EI -> Workplace Diversity & 0.896 & 0.064 & 14.073 & 0.000 \\
\hline
\end{tabular}

Hypothesis-1 postulating positively significant effect of transformational leadership on workplace diversity $(\beta=0.052 ; t=0.428)$ has been rejected, manifesting that there is no effect of transformational leadership on workplace diversity in the banking sector of Pakistan. Similarly, hypothesis-2 postulating that transactional leadership has a significant positive effect on workplace diversity $(\beta=0.055 ; t=0.613)$ has also been rejected. Lastly, hypothesis-3 positing that emotional intelligence positively impacts workplace diversity ( $\beta=$ $0.896 ; t=14.073$ ) has been accepted.

\section{Table 7}

\section{Moderation Analysis using PLS-SEM}

\begin{tabular}{lllll}
\hline Path Relationships & Estimate & S. D. & T-Stats & Prob. \\
\hline H4: TL x OC -> Workplace Diversity & -0.345 & 0.107 & 3.220 & 0.001 \\
H5: TRL x OC -> Workplace Diversity & 0.309 & 0.095 & 3.243 & 0.001 \\
H6: EI x OC -> Workplace Diversity & -0.020 & 0.081 & 0.243 & 0.404 \\
\hline
\end{tabular}

Hypothesis- 4 was positing that OC significantly moderates the relationship between transformational leadership and workplace diversity $(\beta=-0.345 ; t=3.220)$ has been accepted. However, organizational culture negatively moderates the relationship between TL and diversity, manifesting that improving the organizational culture suppresses workplace diversity in the banking sector of Pakistan. Hypothesis- 5 postulating that OC significantly moderates the relationship between transactional leadership and workplace diversity $(\beta=0.309 ; t=3.243)$ has been accepted. It manifested that organizational culture plays a critical role in developing positive workplace diversity in the banking sector of Pakistan. Lastly, hypothesis- 6 hypothesizing that OC significantly moderates the 
relationship between emotional intelligence and workplace diversity $(\beta=-0.020 ; t=0.243)$ has been rejected, manifesting that there is no moderating role of $O C$ on the relationship between emotional intelligence and diversity in the banking sector of Pakistan.

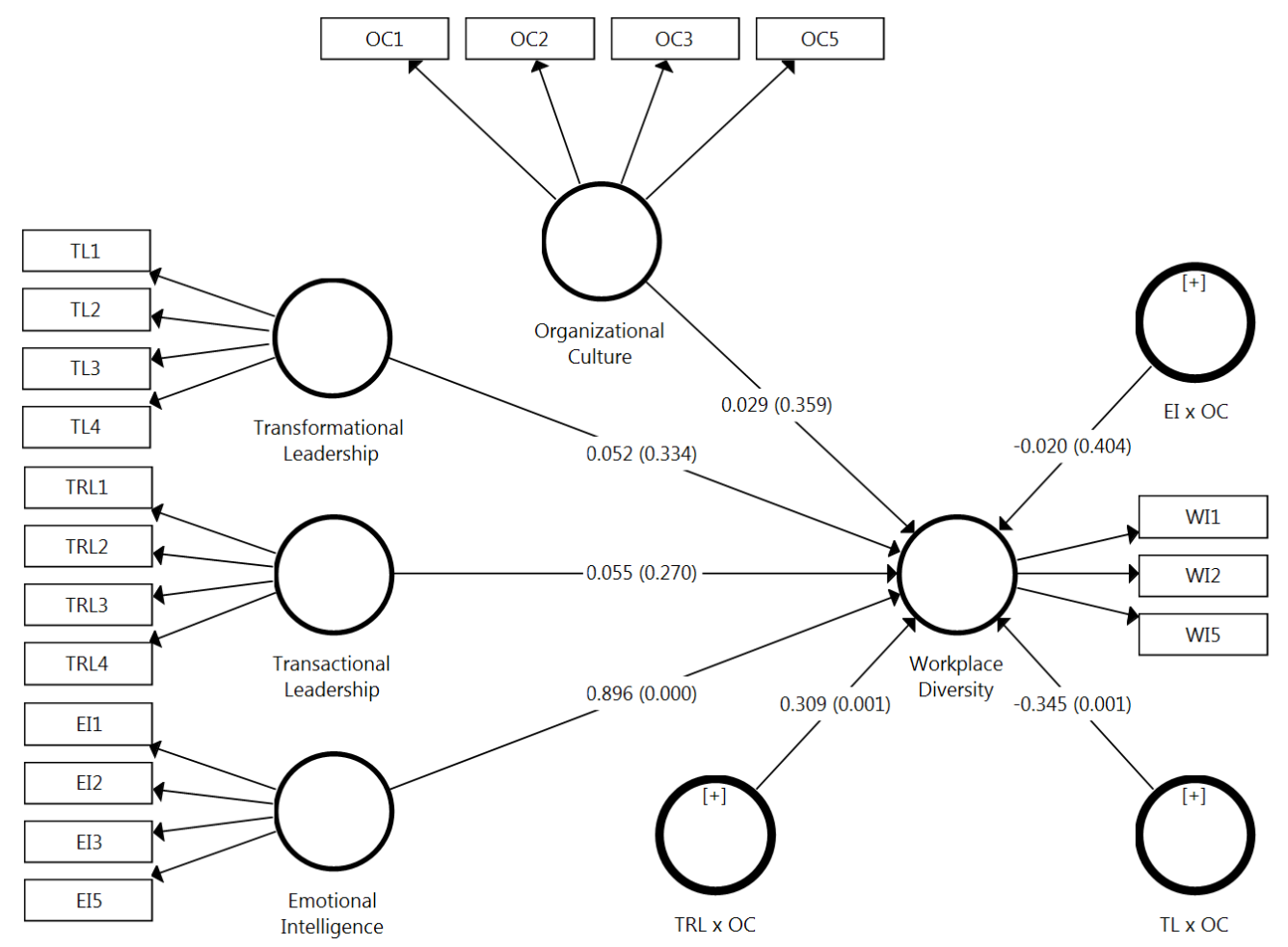

Figure 2: PLS Bootstrapping

\section{Discussions}

The current research has examined the determinants of workplace diversity using different leadership and organizational factors. For instance, transformational leadership $(T L)$ has a positive but insignificant effect on workplace diversity. This result has also been found in different researches. The basic concept of diversity comprises work experience, age, gender, and education and develops workplace diversity (Walumbwa, Wu, \& Ojode, 2004). Similarly, Raad (2019) identified that this workplace diversity has been insignificantly affected by transformational leadership and cannot help develop the diverse environment in an organization. Besides, Chen, Ning, Yang, Feng, and Yang (2018) stated that TL can be based on a paradoxical perspective and that this concept refers that both TL and TRL have positive and negative effects that can coexist. The paradoxical leadership has an insignificant effect on diversity. This insignificant effect might be due to the negligence of the organization that it does not properly engage in training the leaders and eventually it results in not affecting the diversity in the environment (Li, She, \& Yang, 2018).

Transactional leadership refers to how the leaders motivate their employees based on their benefits and personal desires. The result has identified that transactional leadership (TRL) has a positive but insignificant effect on workplace diversity. This result is in line with Mickson et al. (2020) that an increase in TRL cannot increase diversity as the leaders might not be providing good benefits or incentives to raise the diversity. Besides, the TRL has been identified as an essential factor, but it can sometimes be insignificant as the employees might not be delighted with the advantages or worth of the task in which the employees are engaged (Blau, 1968).

Moreover, emotional intelligence (EI) refers to the ability to process emotional information accurately and efficiently and manage it properly(Mayer \& Cobb, 2000). This research has found that emotional intelligence has a positive effect on workplace diversity. This research has been in line with Arnold (2019) that an increase in EI can also increase workplace diversity. Besides, the presence of EI has been identified as an essential factor in any given environment as people interact with each other, and it can enhance the diversity in the environment (Gardenswartz, Cherbosque, \& Rowe, 2010). Also, Clark and Polesello (2017) stated that EI could help managers overcome and solve the complexities related to 
workplace diversity. Similarly, Oyewunmi (2018) identified the significant relationship between these two factors and stated that emotional intelligence might be a leveraging factor that can help in improving diversity in the workplace.

Furthermore, the organizational culture (OC) refers to the specific shared values, assumptions, and beliefs that can affect employees' thinking and behavior (Konrad). This research has identified that organizational culture has a positive and significant moderation effect between transactional leadership and workplace diversity. This result has been in line with Chuang, Church, and Zikic (2004) that the presence of OC can help the managers further develop this relationship. Similarly, Whitfield and Landeros (2006) stated that good and positive OC could help organizations effectively improve their diversity. Also, Guillaume, Dawson, Otaye-Ebede, Woods, and West (2017) stated that OC could positively influence creating diversity in the environment and help achieve its benefits.

The research also identified that OC plays a negative and significant moderating role between transformational leadership and workplace diversity. This result is in line with Çelik (2018) that the presence of OC can decrease the role of TL in today's diverse environment as the culture could not be good in the organization. Similarly, Martin (2014) stated that OC could be a negative factor towards the development of diversity as an increase in interpersonal conflict might decrease the effect of leadership towards diversity. Additionally, OC has been a negative and insignificant moderation factor between emotional intelligence and workplace diversity. This result has been in line with Sethi et al. (2021) that organizational culture might not be a helpful factor towards the development of this relationship. Also, Mazur (2014) identified that OC could not help improve this relationship because there might not be enough EI present in the organization that can enhance the diversity in their environment.

\section{Conclusion}

The current study was focused on the banking sector of Pakistan, Pakistan, to ensure the importance of workplace diversity and organizational culture in the context of transformational leadership, transactional leadership, and emotional intelligence. The results of the study were carried out through the usage of PLS-SEM. The applied methodology in the current study was derived from a quantitative approach and causal research design. The study results showed that the relationship between transformational leadership and workplace diversity was positively insignificant as well as the relationship between transactional leadership and workplace diversity was also found to be positively insignificant. In comparison, the relationship between emotional intelligence and workplace diversity was found to be positively significant. In the relationship where organizational culture was determined as a moderator, the relationship between transformational leadership and workplace diversity was negatively insignificant, while the relationship between transactional leadership and workplace diversity was positively significant. Lastly, the relationship between emotional intelligence and workplace diversity was found to be negatively significant.

\subsection{Recommendations}

The findings emphasized the importance of developing transformational leadership, which improves organizational identity among employees by making them feel included, believing they are a part of the team, and recognizing their roles, thereby increasing workplace diversity. As a result, the findings of this study suggest that managers can aid in the development of their employees' organizational identities by training leaders to demonstrate transformational leadership behaviors. Like, inspirational motivation and intellectual stimulation among lower hierarchy employees, and by doing everything possible, such as displaying familiar behavior patterns, ensure that employees recognize fairness in how tasks can be performed and how workload sheds due to workplace diversity.

Moreover, results obtained upon the current research discovered that transactional leadership also upholds a positive but insignificant workplace diversity. As a result, the current study makes the following suggestions to managers that can make the best use of increasing workplace diversity. Firstly, managers are recommended to ensure transparency 
when identifying roles and expectations of the task amongst employees. Secondly, establish reward systems upon effective outcomes. Thirdly, state the punishments with utmost clarity. However, punishment should fit the employee's transgression. Lastly, monitor employees so that if they face any complications managers, can address them on time, remind them of rewards and encourage them.

As the findings of our study show, team members' emotional intelligence plays a critical role in addressing diversity issues to increase workplace diversity that may aid in the increment of team unity and task outcomes performed by teams. As the findings revealed, emotionally intelligent team members can better deal with their differences and fully realize the creative potential of their disparate thoughts, moral standards, and perceptions. Using this information, managers may ensure that their existing employees receive training sessions on emotional intelligence to help them become more aware of and regulate their own and others' emotions. In addition to that, the study suggests another reasonable step for managers that may enable them to priorities emotional intelligence during the hiring of employees or when promoting deserving employees.

Furthermore, all the factors mentioned above impact workplace diversity by moderating the impact of organizational culture. The current findings show that organizational culture enhances these 3 factors as these factors then help develop workplace diversity. Therefore, the study suggests managers with the following prospects that may help to improve organizational culture. Managers can first establish meaningful values and then communicate these values amongst employees to have a clear-cut idea of what is vital to the company. Managers are suggested to give employees appropriate and timely information and the right tools and time, which may help them succeed.

\section{References}

Ab Hamid, M., Sami, W., \& Sidek, M. (2017). Discriminant validity assessment: Use of Fornell \& Larcker criterion versus HTMT criterion. Paper presented at the Journal of Physics: Conference Series.

Ali, I. S. (2021). A Correlational Study of Organizational Culture and Workforce Diversity \& Competitiveness in a Challenging Global Educational Environment. International Transaction Journal of Engineering, Management, \& Applied Sciences \& Technologies, 12(4), 1-15.

Andoh, J. S., Ghansah, B., Okogun-Odompley, J. N., \& Benuwa, B.-B. (2019). Impact of Workplace Diversity on Employee Performance: A Case of Some Selected Private Universities in Ghana. International Journal of R\&D Innovation Strategy (IJRDIS), 1(2), 31-43.

Anglim, J., Sojo, V., Ashford, L. J., Newman, A., \& Marty, A. (2019). Predicting employee attitudes to workplace diversity from personality, values, and cognitive ability. Journal of Research in Personality, 83, 103865.

Arnold, S. (2019). A Quantitative Descriptive-Comparative Study: The Relationship between Emotional Intelligence and Workplace Diversity. University of Phoenix,

Aydin, B., \& Ceylan, A. (2009). The effect of spiritual leadership on organizational learning capacity. African Journal of Business Management, 3(5), 184-190.

Bana, W. M. (2016). Effect of organizational culture on workplace diversity in public universities in Kenya. International Journal of Education and Research, 4(8), 241-256.

Bass, B. M. (1990). From transactional to transformational leadership: Learning to share the vision. Organizational dynamics, 18(3), 19-31.

Bass, B. M., \& Bass Bernard, M. (1985). Leadership and performance beyond expectations.

Bastari, A., Eliyana, A., \& Wijayanti, T. (2020). Effects of transformational leadership styles on job performance with job motivation as mediation: A study in a state-owned enterprise. Management Science Letters, 10(12), 2883-2888.

Blau, P. M. (1968). Social exchange. International encyclopedia of the social sciences, 7, 452-457.

Blessing, L. T., \& Chakrabarti, A. (2009). DRM, a design research methodology (1st ed.). Verlag London: Springer Science \& Business Media.

Boruah, A. S. (2018). Emotional Intelligence of Higher Secondary Students of Sivasagar District of Assam: A Study of selected Associated Variables. Asian Journal of Research in Social Sciences and Humanities, 8(6), 213-227. 
Brown, M., Brown, R. S., \& Nandedkar, A. (2019). Transformational Leadership Theory and Exploring the Perceptions of Diversity Management in Higher Education. Journal of Higher Education Theory \& Practice, 19(7).

Burns, J. M. (1995). The crisis of leadership. The leader's companion: Insights on leadership through the ages, 8-10.

Campbell, D. T., \& Fiske, D. W. (1959). Convergent and discriminant validation by the multitraitmultimethod matrix. Psychological bulletin, 56(2), 81-105.

Canagasuriam, D., \& Roulin, N. (2021). The Effect of Organizational Culture on Faking in the Job Interview. Personnel Assessment and Decisions, 7(1), 8.

Çelik, S. (2018). Transformational leadership and organizational culture: Keys to binding employees to the Dutch Public Sector. Vveinhardt, J. Organizational Culture, 145-165.

Chen, Y., Ning, R., Yang, T., Feng, S., \& Yang, C. (2018). Is transformational leadership always good for employee task performance? Examining curvilinear and moderated relationships. Frontiers of Business Research in China, 12(1), 1-28.

Chitra, K. (2017). Dr. Chandra Mohan A, Organizational Culture and Its Influence On Workplace Diversity and Inclusion. International Journal of Civil Engineering and Technology, 8(8).

Chuang, Y. T., Church, R., \& Zikic, J. (2004). Organizational culture, group diversity and intra-group conflict. Team Performance Management: An International Journal.

Clark, J. M., \& Polesello, D. (2017). Emotional and cultural intelligence in diverse workplaces: Getting out of the box. Industrial and commercial training.

Cletus, H. E., Mahmood, N. A., Umar, A., \& Ibrahim, A. D. (2018). Prospects and challenges of workplace diversity in modern day organizations: A critical review. HOLISTICA-Journal of Business and Public Administration, 9(2), 35-52.

Cote, R. (2017). Vision of effective leadership. International Journal of Business Administration, 8(6), 110.

Creswell, J. W. (2002). Educational research: Planning, conducting, and evaluating quantitative. NJ: Merrill Prentice Hall.: Upper Saddle River.

De Meuse, K. P., \& Hostager, T. J. (2001). Developing an instrument for measuring attitudes toward and perceptions of workplace diversity: An initial report. Human Resource Development Quarterly, 12(1), 33-51.

Elramalli, O. M. (2020). Leadership Theories and its Styles: A Review Study. Paper presented at the Econder 2020 3rd. International Economics, Business and Social Sciences Congress.

Farashah, A., \& Blomqusit, T. (2021). Organizational culture and cultural diversity: an explorative study of international skilled migrants in Swedish firms. Journal of Global Mobility: The Home of Expatriate Management Research.

Fornell, C., \& Larcker, D. F. (1981). Structural equation models with unobservable variables and measurement error: Algebra and statistics. Journal of marketing research, 18(3), 382-388.

Gardenswartz, L., Cherbosque, J., \& Rowe, A. (2010). Emotional intelligence and diversity: A model for differences in the workplace. Journal of Psychological Issues in Organizational Culture, 1(1), 7484.

Geisser, S. (1975). The predictive sample reuse method with applications. Journal of the American statistical Association, 70(350), 320-328.

Gouldner, A. W. (1960). The norm of reciprocity: A preliminary statement. American sociological review, 161-178.

Guillaume, Y. R., Dawson, J. F., Otaye-Ebede, L., Woods, S. A., \& West, M. A. (2017). Harnessing demographic differences in organizations: What moderates the effects of workplace diversity? Journal of Organizational Behavior, 38(2), 276-303.

Hair, J. F., Hult, G. T. M., Ringle, C., \& Sarstedt, M. (2016). A primer on partial least squares structural equation modeling (PLS-SEM) (2nd ed.). Thousand Oaks,USA: SAGE Publications.

Hair, J. F., Matthews, L. M., Matthews, R. L., \& Sarstedt, M. (2017). PLS-SEM or CB-SEM: updated guidelines on which method to use. International Journal of Multivariate Data Analysis, 1(2), 107-123.

Hair, J. F., Ringle, C. M., \& Sarstedt, M. (2011). PLS-SEM: Indeed a silver bullet. Journal of Marketing theory and Practice, 19(2), 139-152. 
Hair, J. F., Ringle, C. M., \& Sarstedt, M. (2013). Partial least squares structural equation modeling: Rigorous applications, better results and higher acceptance. Long range planning, 46(1-2), 1-12.

Hair, J. F., Risher, J. J., Sarstedt, M., \& Ringle, C. M. (2019). When to use and how to report the results of PLS-SEM. European Business Review, 31(1), 2-24.

Hair, J. F., Sarstedt, M., Hopkins, L., \& Kuppelwieser, V. G. (2014). Partial least squares structural equation modeling (PLS-SEM) An emerging tool in business research. European Business Review, 26(2), 106-121.

Henseler, J., \& Fassott, G. (2010). Testing moderating effects in PLS path models: An illustration of available procedures. In Handbook of partial least squares (pp. 713-735). Berlin, Germany: Springer.

Henseler, J., Hubona, G., \& Ray, P. A. (2016). Using PLS path modeling in new technology research: updated guidelines. Industrial management \& data systems, 116(1), 2-20.

Henseler, J., Ringle, C. M., \& Sarstedt, M. (2015). A new criterion for assessing discriminant validity in variance-based structural equation modeling. Journal of the academy of marketing science, 43(1), 115-135.

Hermans, C. (2021). Discernment as predictor for transformational leadership: a study of school leaders in Catholic schools in India. Journal of Beliefs \& Values, 1-16.

Hersing, W. S. (2017). Managing cognitive bias in safety decision making: Application of emotional intelligence competencies. Journal of Space Safety Engineering, 4(3-4), 124-128.

Homans, G. C. (1958). Social behavior as exchange. American journal of sociology, 63(6), 597-606.

Imran, R., Fatima, A., Zaheer, A., Yousaf, I., \& Batool, I. (2012). How to boost employee performance: investigating the influence of transformational leadership and work environment in a Pakistani perspective. Middle-East Journal of Scientific Research, 11(10), 1455-1462.

Jackson, L., Heyns, M., \& McCallaghan, S. (2019). Exploring organisational diversity climate with associated antecedents and employee outcomes. SA Journal of Industrial Psychology, 45(1), 110.

Kamales, N., \& Knorr, H. (2019). Leaders with Managing Cultural Diversity and Communication. Asia Pacific Journal of Religions and Cultures, 3(1), 63-72.

Kittikunchotiwut, P. (2019). Role of Transformational Leadership and Transactional Leadership on Organization Innovation. Paper presented at the Proceedings of International Academic Conferences.

Kothari, C. R. (2004). Research methodology: Methods and techniques (2nd ed.). Delhi: New Age International.

Kumari, P., \& Priya, B. (2017). Impact of emotional intelligence on job performance and organizational commitment among bank managers. International Journal of Interdisciplinary and Multidisciplinary Studies, 4(3), 300-311.

Kundu, S. C., \& Mor, A. (2017). Workforce diversity and organizational performance: a study of IT industry in India. Employee Relations.

Li, Q., She, Z., \& Yang, B. (2018). Promoting innovative performance in multidisciplinary teams: The roles of paradoxical leadership and team perspective taking. Frontiers in psychology, 9, 1083.

Libbrecht, N., Beuckelaer, A. D., Lievens, F., \& Rockstuhl, T. (2014). Measurement invariance of the Wong and Law Emotional Intelligence Scale scores: Does the measurement structure hold across Far Eastern and European countries? Applied Psychology, 63(2), 223-237.

Manzoor, F., Wei, L., Nurunnabi, M., Subhan, Q. A., Shah, S. I. A., \& Fallatah, S. (2019). The impact of transformational leadership on job performance and CSR as mediator in SMEs. Sustainability, 11(2), 436.

Marlina, L., Maifizar, A., Rahmadani, I., Maulina, R., Rahmazaniati, L., Husen, T. I., \& Zulkarnain, M. (2021). The Role of Mediating Leadership Morality on the Influence of Organizational Culture on the Internal Control System. Paper presented at the First International Conference on Science, Technology, Engineering and Industrial Revolution (ICSTEIR 2020).

Martin, G. C. (2014). The effects of cultural diversity in the workplace. Journal of diversity management (JDM), 9(2), 89-92.

Masterson, S. S., Lewis, K., Goldman, B. M., \& Taylor, M. S. (2000). Integrating justice and social exchange: The differing effects of fair procedures and treatment on work relationships. Academy of Management journal, 43(4), 738-748. 
Mayer, J. D., \& Cobb, C. D. (2000). Educational policy on emotional intelligence: Does it make sense? Educational psychology review, 12(2), 163-183.

Mazur, B. (2014). Building diverse and inclusive organizational culture-best practices: A case study of Cisco Co. Journal of Intercultural Management, 6(4.1), 169-179.

McCallaghan, S., Jackson, L. T., \& Heyns, M. M. (2019). Transformational leadership, diversity climate, and job satisfaction in selected South African companies. Journal of Psychology in Africa, 29(3), 195-202.

Memon, S. B., Qureshi, J. A., \& Jokhio, I. A. (2020). The role of organizational culture in knowledge sharing and transfer in Pakistani banks: A qualitative study. Global Business and Organizational Excellence, 39(3), 45-54.

Mickson, M. K., Anlesinya, A., \& Malcalm, E. (2020). Mediation role of diversity climate on leadership and job satisfaction in the Ghanaian public sector. World Journal of Entrepreneurship, Management and Sustainable Development.

Miller, D. W., Ngunjiri, F. W., \& LoRusso, J. D. (2017). Human resources perceptions of corporate chaplains: enhancing positive organizational culture. Journal of Management, Spirituality \& Religion, 14(3), 196-215.

Ng, E. S., \& Sears, G. J. (2020). Walking the talk on diversity: CEO beliefs, moral values, and the implementation of workplace diversity practices. Journal of Business Ethics, 164(3), 437-450.

Obuma, G. E., \& Worlu, G. O. (2017). Workplace diversity and employee engagement of banks in rivers state, Nigeria. pathology, 3(6).

Ogbor, J., \& Orishede, F. (2018). Ethical Leadership and the Management of Workforce Diversity. LEADERSHIP, SECURITY AND NATIONAL DEVELOPMENT, 301.

Oyewunmi, A. E. (2018). Normalizing difference: Emotional intelligence and diversity management competence in healthcare managers. Intangible Capital, 14(3), 429-444.

Podsakoff, P. M., Bommer, W. H., Podsakoff, N. P., \& MacKenzie, S. B. (2006). Relationships between leader reward and punishment behavior and subordinate attitudes, perceptions, and behaviors: A meta-analytic review of existing and new research. Organizational Behavior and Human Decision Processes, 99(2), 113-142.

Raad, G. (2019). The Relationship between Workgroup Diversity and Employees Work Performance in Lebanon.

Riaz, A., \& Haider, M. H. (2010). Role of transformational and transactional leadership on job satisfaction and career satisfaction. Business and Economic horizons, 1(1), 29-38.

Sashkin, M., \& Rosenbach, W. E. (1990). Organizational culture assessment questionnaire: Marshall Sashkin.

Saunders, M., Lewis, P., \& Thornhill, A. (2009). Research methods for business students (6th ed.). england: Pearson education.

Scarborough, W. J., Lambouths III, D. L., \& Holbrook, A. L. (2019). Support of workplace diversity policies: The role of race, gender, and beliefs about inequality. Social Science Research, 79, 194210.

Schaffer, B. S. (2019). Examining reactions to workplace diversity: The role of dissimilarity-attraction in teams. Canadian Journal of Administrative Sciences/Revue Canadienne des Sciences de I'Administration, 36(1), 57-69.

Sekaran, U., \& Bougie, R. (2010). Research for Business-A Skill Building Approach (5th ed.). New York, NY: John-Wiley and Sons.

Sethi, B., Vito, R., \& Ongbanouekeni, V. (2021). Organizational Culture, Diversity, and Employees' Health in Social/Human services: A Systematic Review. International Health Trends and Perspectives, 1(1), 74-95.

Setyaningrum, R. P. (2017). Relationship between servant leadership in organizational culture, organizational commitment, organizational citizenship behaviour and customer satisfaction.

Shapira-Lishchinsky, O. (2018). Ethical Aspects of Transactional, Transformational, and Authentic Leadership Styles. In International Aspects of Organizational Ethics in Educational Systems: Emerald Publishing Limited.

Shifnas, M., \& Sutha, J. (2016). Impact of effective workforce diversity management on employees' performance in construction sector. 
Stone, M. (1974). Cross-validatory choice and assessment of statistical predictions. Journal of the royal statistical society. Series B (Methodological), 36(2), 111-147.

Suharnomo, A. Y., Wahyudi, S., \& Wikaningrum, T. (2017). A systematic literature review of managing workplace diversity for sustaining organizational competitive advantage. International Journal of Mechanical Engineering and Technology, 8(12), 398-406.

Tamunomiebi, M. D., \& John-Eke, E. C. (2020). Workplace Diversity: Emerging Issues in Contemporary. International Journal of Academic Research in Business and Social Sciences, 10(2).

Taylor, A. S. (2015). Transformational leadership, diversity, and creativity at work: A moderated mediation model.

Uche, C. B., Onokala, U., Okundalaiye, H., George, B., \& Oni, O. (2020). WORKPLACE DIVERSITY AND ORGANIZATIONAL CULTURE IN THE NIGERIA'S MARITIME INDUSTRY. UNILAG Journal of Business, 6(2), 120-138.

Walumbwa, F. O., Wu, C., \& Ojode, L. A. (2004). Gender and instructional outcomes: The mediating role of leadership style. Journal of Management Development.

Whitfield, G., \& Landeros, R. (2006). Supplier diversity effectiveness: does organizational culture really matter? Journal of Supply Chain Management, 42(4), 16-28.

Yang, Y.-F. (2014). Studies of transformational leadership: Evaluating two alternative models of trust and satisfaction. Psychological reports, 114(3), 740-757. 